\title{
Revenue Cycle Management in the Wake of EMR Implementation: A Competing Logics Perspective
}

\author{
Rajendra Singh \\ University of Oklahoma \\ rsingh@ou.edu
}

\author{
Alexandra Durcikova \\ University of Oklahoma \\ $\underline{\text { alex@ou.edu }}$
}

\author{
Lars Mathiassen \\ Georgia State University \\ lars.mathiassen@ceprin.org
}

\begin{abstract}
The health information technology (HIT) literature has focused on how healthcare organizations use electronic medical record (EMR) systems and other clinical IT for care delivery and coordination. However, few studies have examined how implementation of these technologies impact the organizations' revenue cycle management (RCM) and consequent financial sustainability. Against that backdrop, we draw on institutional logics perspective to analyze experiences from two action research engagements that leveraged EMR implementations in medical clinics to improve RCM. As a result, we identify four coexisting yet competing logics-logic of care, logic of business, logic of management, and logic of technology - that shaped how the clinics addressed challenges in their revenue cycle. While IT transformed practices and information exchanges, the competing logics shaped the clinics' RCM in the wake of their EMR implementation. We conclude with contributions to research and practice.
\end{abstract}

\section{Introduction}

Health information technology (HIT) research has focused on the implementation and use of electronic medical record (EMR) systems and other clinical IT in healthcare organizations. These HITs improve patient care outcomes by enhancing efficiency, reducing errors, improving patient safety and clinical quality, facilitating information exchanges, and reducing cost [1-3]. However, EMR and other clinical IT represent only part of the HIT bundle needed to deliver care to patients and to support day-to-day operations in a healthcare organization [4]. An equally important, yet understudied, research area includes the IT that supports the revenue cycle - a complex enterprisewide process that includes all activities related to delivering health-care services to patients and getting reimbursed for those services [5]. The revenue cycle- which includes activities such as patient registration, medical charge coding, billing, payment posting, and revenue recovery $[6,7]$ - must function smoothly to generate stable cash flow [8]. As such, effective revenue cycle management (RCM) with appropriate IT support is critical to a healthcare organization's financial sustainability.

Recent academic and practitioner literature has shown that healthcare organizations face an ongoing struggle with revenue cycle-related issues [7, 9], suggesting that these struggles continue even when the organizations have achieved some level of IT maturity. One explanation is that the healthcare environment is extremely dynamic, with ongoing policy and regulatory changes, mandated technology requirements (e.g., following the US HITECH Act in 2009), and the rapid pace of advances in IT. Another explanation is the complex nature of the healthcare environment with multiple levels of intermediaries between physicians and patients, including public health agencies, insurance companies, labs, pharmacies, and coding and billing service providers. However, these contextual explanations do not fully account for the struggle that healthcare organizations face in managing their revenue cycle. To focus on internal organizational explanations and observing that EMR systems play a crucial role in shaping activities throughout healthcare organizations [10-12], we ask: How does the implementation of EMR systems impact RCM and financial sustainability in healthcare organizations?

We examine evidence from two action research (AR) engagements - one at a family practice clinic in the southeastern US and another at a psychiatry practice clinic in the southcentral US - that successfully implemented an EMR system with different consequential RCM approaches. The family practice followed a "best-of-breed" approach [13] and selected an EMR system that the physician rated the highest for ease-of-use [14], although it did not have integrated RCM functionality. The psychiatry practice followed a fully integrated approach from the start, 
with a single system providing both EMR and RCM functionality. In both cases, the EMR implementation and assimilation was seamless, while the RCM implementation and ongoing operation was problematic and caused severe challenges. Contrary to the assumption that health IT solutions in healthcare organizations provide almost immediate business value, we find that no matter which approach was selected, the RCM solution continued to cause substantial challenges.

We draw on the institutional logics perspective to analyze the two AR engagements. Institutional logics refers to the "socially constructed patterns of symbols and material practices, assumptions, values, beliefs, and rules by which individuals and organizations produce and reproduce their material subsistence, organize time and space, and provide meaning to their social reality" [15]. Institutional logics allow individuals and organizations to provide meaning to actions and structure to conflicts [16] by guiding and constraining decisions about tasks and by channeling attention to particular issues [17]. To reflect the uncertain and complex nature of the healthcare context, we draw on the notion of competing institutional logics [18-20] in healthcare [21-23].

As a result, we contribute to the HIT literature by identifying the institutional logics related to the healthcare revenue cycle. We identify four co-existing yet competing logics - logic of care, logic of business, logic of management, and logic of technology - that shaped how the two clinics managed their revenue cycle after successfully implementing an EMR system. We find that the decision-makers at times managed to reconcile the competing logics, while at other times they had to invest time and resources to overcome related constraints. We extend prior research on competing logics in EMR implementation [22] to explain how the logics shape healthcare organizations' IT-enabled RCM in the wake of EMR implementations.

\section{Literature review}

\subsection{Revenue cycle management challenges}

Managing a stable revenue flow through effective $\mathrm{RCM}$ practices is challenging. In the case of healthcare organizations - especially in the US - this challenge is exacerbated by the uncertainty and complexity of the healthcare environment, where administrative costs associated with billing and insurance-related activities can account for between $3 \%$ and $25 \%$ of patient service revenue [24]. Internally, RCM involves coordination and exchange of information between departments focused on patient care and other supporting departments such as billing. Further, the documentation of care provision (e.g., determining which level of code to use for a particular encounter) amidst multi-year audits by different payers results in further uncertainty and complexity [6]. Externally, RCM-related departments routinely interact with payers (e.g., to request for prior authorizations for treatment or medication) as well as outsourced coding, billing, and other services. Thus, for each patient encounter, the uncertainty and complexity of delivering care as well as documenting and communicating clinical and financial information to numerous internal and external partners makes the RCM very challenging.

Other reasons that make RCM challenging include increased federal and state regulations, the expected social responsibility of hospitals to care for patients regardless of their ability to pay, increased reporting requirements, and decreasing reimbursements. Moreover, reimbursements can take months and may be substantially lower than the claimed charges, thereby straining cash flow. Another challenge relates to the fact that physicians and nurses concern themselves with treating patients, not primarily with the cost of treatment, leaving the problem of managing efficiency, cost containment, and service volume to financial administrators [25].

\subsection{IT-enabled RCM}

RCM-focused IT systems have been used in hospitals since at least the late 1970s [26]. Initially, these systems focused on automating data-intensive and rule-based functions such as patient billing. As reimbursement policies became more complex and as hospitals were pushed by successive legislation and market competition to reduce their costs, RCM vendors began offering standalone systems with functionalities that complemented EMR systems (e.g., medical charge coding, patient scheduling, and patient registration). These systems gained popularity in the mid-1990s, following the availability of low-cost personal computers and the development of clientserver and cloud-based RCM applications.

Enterprise-wide integration of these IT systems remains a big challenge as hospitals and other healthcare organizations have adopted solutions by different RCM vendors who promised "best-of-breed" [13] functionalities. Complete end-to-end integration of RCM applications (especially coding and billing) with EMR systems is very complex and costly. Limited or partial integrations are more common, for example, pushing the diagnosis and procedure codes (recorded by the physician in the EMR system) to the billing system.

IT-enabled RCM is critical to improving hospital performance [6]. For example, patient scheduling 
systems help optimize patient flow, registration systems capture insurance and demographic information needed for billing, and practice management systems improve the accuracy of medical charge entry, claim submission, and account reconciliation [7]. The practitioner literature provides anecdotal evidence on the positive impact of IT use in revenue cycle activities [27]. Except for a few recent studies $[7,8]$, the IS literature on health IT has paid little attention to RCM, despite computerized billing being among the first IT systems in hospitals and one of the most commonly used [26, 28].

\section{Theoretical background}

\subsection{Institutional logics}

Institutional logics refer to the practices and belief systems that shape how individuals and groups engage in an organizational, societal, or political context [16, 29]. While an institution represents a set of culturally and historically grounded social practices and behavioral patterns, institutional logics establish the rationale that underpins institutions and provides meaning and organizing principles for institutionalized practices [30-32]. As such, the institutional logics perspective allow researchers to examine "how decision making and behavior are interpenetrated with an array of wider institutional influences" and it can help understand how values, behavioral norms, and assumptions of organizational actors influence organizational and institutional change over time [20,21].

Contemporary institutional analyses have characterized organizations as institutionally plural, and subject to multiple, often contradictory institutional logics [18-20]. Several studies have examined such competing logics in a variety of contexts, including family-managed firms [33], community banking [34], higher education [35], architecture [36], culinary professions [37], and accounting and law [38].

Various IS studies have also used the competing institutional logics perspective, e.g., to examine enterprise information system implementation [32, 39], independent third-party app development [40], enterprise architecture adoption [41], digital infrastructure [42], and digital innovation [43].

\subsection{Institutional logics in healthcare}

The institutional logics perspective has also been applied to examine the plurality and complexities of healthcare contexts. For example, a landmark book investigated how health care is shaped by the institutional logics of the market, the logic of the democratic state, and the professional logic of medical care [44]. Further, it discussed how US healthcare has transformed from a field dominated by professional logics to one where multiple logics co-exist and no single logic dominates. Another study examined medical professionalism and business-like healthcare in Canada, and found that the struggles among the actors holding different logics resulted in power being distributed between the physicians and the statecreating a counterbalancing effect of contentious coexistence [21]. Researchers have also used the institutional logics perspective to examine the challenges of implementing an EMR system in a Danish hospital [45]. In the context of medical education, two competing logics - of care and science-have been identified; these are "supported by distinct groups and interests, fluctuate over time, and create dynamic tensions about how to educate future medical professionals" [46]. A recent study identified four institutional logics related to the adoption and use of EMR systems in hospitals and private practices-medical professionalism, private sector managerialism, technical design, and regulatory oversight [22]. They found that the intertwining ("reticulation") of practices afforded by the EMR systems engendered complementarity and conflict between the logics.

\section{Research methodology}

Considering that the primary driver of the two client engagements was the need to improve RCM performance in the wake of EMR implementations, we selected AR [47-50] as our research method. AR is a collaborative, theory generating, situational methodology that is particularly well suited for bridging theory and practice in organizational settings [50]. Thus, combining theory generation with researcher intervention to solve immediate organizational problems [51], AR seeks to "contribute to both the practical concerns of people in an immediate problematic situation and to the goals of social science by joint collaboration within a mutually acceptable ethical framework" [47]. Further, as a particular form of engaged scholarship [52], AR affords a deep understanding of the problem context and the perspective of key stakeholders. Several studies have successfully applied AR to study and implement IT-enabled organizational change [53-56]. AR has also proven useful in investigating issues related to the implementation and use of health IT in general [57-60], and RCM in particular [7].

Relying on the systematic interaction between the problem-solving cycle aimed at addressing RCM issues and the research cycle aimed at developing new knowledge [61, 62], two researchers independently 
designed and enacted multiple IT-based interventions to improve RCM performance at the two clinics. Despite its utility, AR presents specific challenges, including the need for researchers to have an in-depth understanding of the local context and to adapt the research design and specific interventions to accommodate changes in that context [63]. To address these challenges, the two researchers worked closely with the respective physicians to gain an in-depth understanding of the day-to-day workings of RCM and participated actively in the problem-solving process for an extended period (nearly 6 years in the family practice clinic and over 18 months in the psychiatry clinic).

Data collection and analysis followed the fivestage canonical AR process model: diagnosing, action planning, action taking, evaluation, and specifying learning following a researcher-client agreement [50, 64]. Next, we describe the investigative context of the two AR studies, followed by details of the AR cycles.

\subsection{Family practice clinic}

The family practice clinic was established in 2014 by Dr. M. to provide urgent, preventative, and chronic disease management services to mainly adult patients. She was an independent, solo provider with 3-6 fulltime employees, including front desk staff, medical assistants, and a nurse practitioner (NP). Before establishing the private practice, Dr. M had worked for several years in hospital-based in-patient units and out-patient clinics.

In spring 2014, when Dr. M was planning for the new clinic, she (and her spouse, who is one of the researchers) considered several EMR options. Ultimately, she chose an affordable, cloud-based EMR (FP-EMR) that had a "clinician-friendly" user interface and provided essential functionalities related to care-delivery, including patient scheduling, eprescribing, and lab integrations (to send lab orders and receive results). While ease-of-use [14] was the most important criterion for selection, FP-EMR also rated highly on maintainability, training, technical support, and being easy-to-learn. FP-EMR did not have an integrated RCM system, but the vendor recommended a third-party practice management system (FP-Sys1) with which it had partial integration to provide a workable solution. Since Dr. M did not have previous medical billing experience or an employee with requisite skills, she chose the FP-Sys 1 vendor as the provider of billing and practice management as an outsourced service (for which the vendor charged $6 \%$ of collected revenue). Accordingly, FP-Sys1 would receive patient visitrelated codes (from FP-EMR), and a remote team would submit the claims to payers, receive the electronic remittance advice of how the insurance company has processed a claim, track payments received, and send patient bills for the balance amount.

Over the next 6 years, Dr. M struggled with RCM and implemented various systems (including moving from FP-Sys 1 to FP-Sys2 and then finally to FP-Sys3) to address RCM challenges. During this period, Dr. M was satisfied with the FP-EMR system and the functionalities it afforded.

\subsection{Psychiatry practice clinic}

The psychiatry clinic was established in 2001 by Dr. P, who specialized in adult, adolescent, and child psychiatry. He had an independent, solo practice with 2-3 full-time staff members until November 2018 when he was joined by a psychiatry NP, who apprenticed for six months before starting to see patients on her own. This required that claims be submitted separately for Dr. P and the NP so they could be reimbursed for their services. However, their EMR-RCM system did not support this functionality.

Initially, Dr. P was using an MS-DOS-based integrated EMR and RCM system (PP-Sys1) that stored patient's demographic, insurance, and schedule related information. While PP-Sys1 allowed submitting most claims to insurance companies, some claims had to be submitted manually on insurance company websites. Further, PP-Sys1 was unable to receive electronic remittance advice from payers. Instead, Dr. P received a paper-based statement (called an explanation of benefit) for each claim, which was then manually entered into PP-Sys 1 by a billing company. The billing company also submitted the claims to the insurance companies and charged $7.5 \%$ of the collected revenue for its services. Payments were received either as checks or as direct deposits to Dr. P's bank. Given the limited functionality of PPSys1 and the need for manual processing of some claims, around $15 \%$ of claims were never submitted to insurance companies. Moreover, it was difficult to determine which claims remained unsubmitted.

Starting in spring 2019, Dr. P, his office manager, and one of the researchers started evaluating different fully integrated, cloud-based EMR-RCM systems that would allow seamless submission of claims and receive electronic remittance advice. After careful evaluation, Dr. P selected PP-Sys2. The implementation started in June 2019 and was fully functional by Sept 2019, except some integration issues with two insurance companies that remained until Dec 2019. As of June 2020, PP-Sys2 supported a full integration of the functionalities needed for clinical care (e.g., patient demographic information, scheduling, clinical notes, prescription refills) with those needed to submit claims and receive payments. 


\section{Empirical Analyses}

\subsection{Analysis of AR cycles}

The AR at the family practice clinic was conducted across three cycles between fall 2014 and spring 2017, and at the psychiatry clinic across one cycle between spring 2019 and summer 2020. Tables 1 and 2 offer a detailed analysis of the activities and events involved in these cycles.

Table 1. AR in family practice (FP) clinic

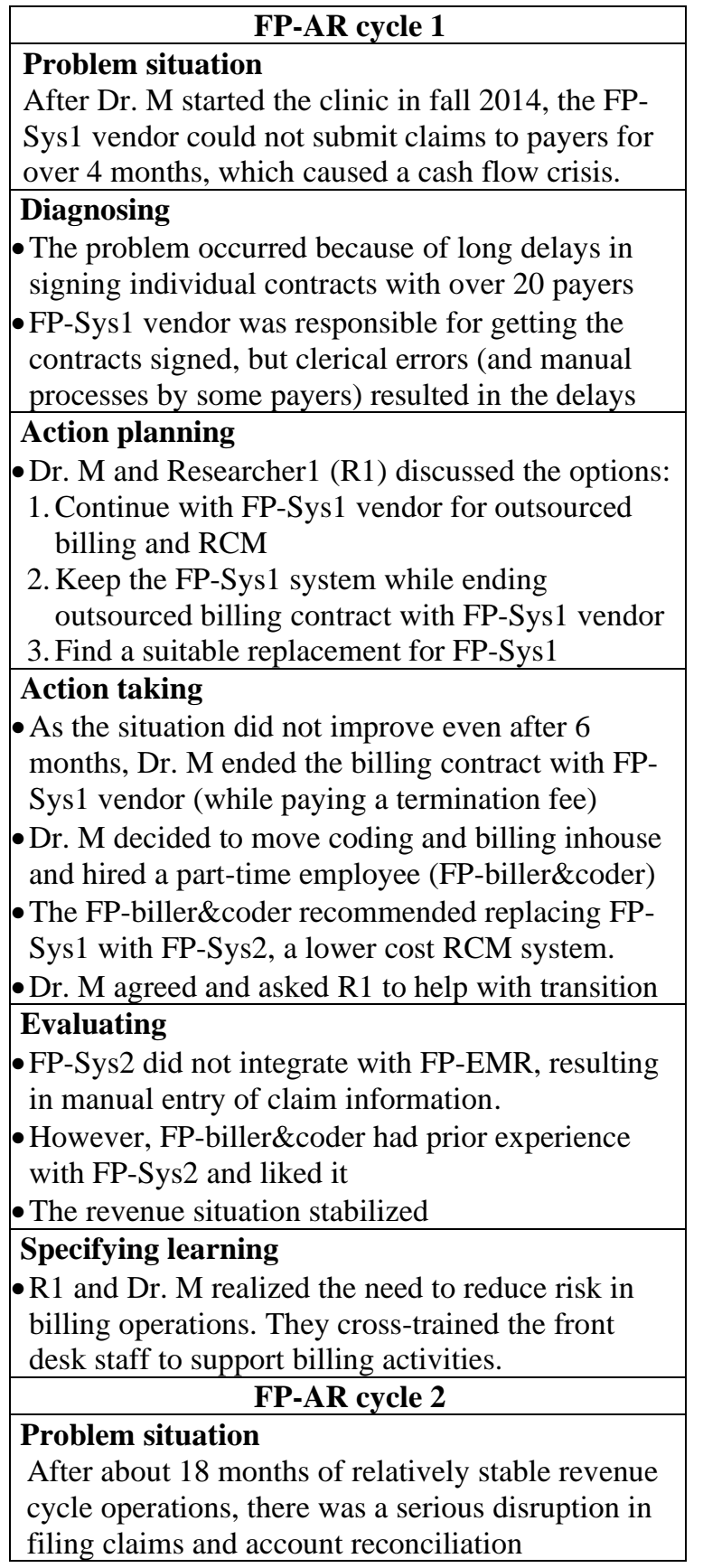

\section{Diagnosing}

- The FP-biller\&coder left (to attend to some personal issues)

\section{Action planning}

- Dr. M and R1 considered different options but decided to continue with FP-Sys2 to minimize risk - Dr. $\mathrm{M}$ decided to hire a biller/coder.

\section{Action taking}

- Dr. M interviewed several candidates and hired a certified medical coder (FP-coder). FP-coder said she could also manage billing.

\section{Evaluating}

- The quality of coding improved. However, many claims remained pending and patient accounts unreconciled, resulting in significant revenue loss.

- Dr. M discussed the situation with FP-coder, who informed that she had difficulty working with FPSys2. She resigned soon after.

- A new person (FP-biller), certified in billing, was hired to expedite the claims. The billing situation improved, but this employee also left within a few months, citing the large amount of manual entry required with FP-Sys2.

\section{Specifying learning}

- The lack of integration between FP-EMR and FPSys2 had become a bigger issue than previously understood, as it had now led to two key staff departures within a short period.

\section{Problem situation} FP-AR cycle 3

The FP-biller's departure led to severe RCM disruption. Dr. M was very distressed by this situation. For almost 3 years, she had seen 15-18 patients daily. Yet, she could not make enough revenue to pay her staff and for the medical supplies, let alone draw a consistent salary.

\section{Diagnosing}

- The RCM disruption occurred, in part, due to lack of integration between FP-EMR and FP-Sys2.

- The inability to hire staff that could do both coding and billing, along with staff departures, contributed to the disruption.

\section{Action planning}

- Dr. M. and R1 considered replacing the FP-EMR with an integrated EMR-RCM system.

- They first discussed the matter with the FP-EMR vendor and explored if RCM functionality would soon be included

- The FP-EMR vendor recommended a third-party practice management system (FP-Sys3) with which it had better integration (vis-à-vis FP-Sys1).

\section{Action taking}

- To avoid major disruption in clinical care delivery that would result from replacing FP-EMR, Dr. M decided to continue with FP-EMR 
- Dr. M decided to replace FP-Sys2 with FP-Sys3.

- Fortunately, FP-biller\&coder who had previously worked for over 18 months rejoined the clinic (on condition that she could work from home). She also agreed to help with FP-Sys3 transition.

\section{Evaluating}

- The revenue cycle stabilized after a few months - In response to complaints from many patients over the previous months that their bills were inaccurate, Dr. M asked FP-biller\&coder to review all the claims and patient bills in the past 9 months. Although necessary, this decision was costly as FP-biller\&coder was paid hourly

- As of April 2020, FP-clinic was still using FPSys3 (and FP-biller\&coder supported remotely)

\section{Specifying learning}

- R1 and Dr. M reflected on the ongoing RCM problems caused by the initial decision to select FP-EMR. However, Dr. $\mathrm{M}$ and her medical assistants were very satisfied with FP-EMR and were wary of replacing it with a fully integrated EMR-RCM system

\section{Table 2. AR in psychiatry practice (PP) clinic}

\section{Problem situation}

$$
\text { PP-AR cycle }
$$

In March 2019, Researcher2 (R2) and Dr. P identified the following issues:

1. The outsourced RCM's staff could not explain how a patient's account balance was calculated. It was also unclear which claims were submitted and paid by insurance payers.

2. Prescription refill requests required several manual steps.

3. Appointment reminders were labor-intensive as patients were called 2 days before appointment.

\section{Diagnosing}

- The limited functionality of MS-DOS based EMR (PP-Sys1) was the main cause of the RCM issues

\section{Action planning}

- Dr. P and R2 discussed the need to replace PPSys1. They identified the most important characteristics of a new EMR-RCM system, including a cloud-based architecture, multiple providers schedules, automated patient reminders, fully integrated billing, e-prescribing, ease of scheduling and rescheduling patients, and ability to create templates and macros. These criteria were used to evaluate 10 EMR-RCM systems. After vendor demonstrations and cost/functionality evaluation, Dr. P chose PP-Sys2 in June 2019.

\section{Action taking}

- The PP-Sys2 vendor helped with implementation and training. The office manager was first trained and together they set up the basic functionality.

\begin{tabular}{|l|}
\hline Although the PP-Sys2 vendor promised billing \\
integration within a month, it took several months \\
for the new clearinghouse to begin sending claims. \\
\hline Evaluating \\
- R2 suggested documenting each business process. \\
- Intensive training initiated for billing staff on \\
billing and claim resolution. \\
\hline Specifying learning \\
- Dr. P and R2 reflected on the PP-Sys2 \\
functionality and considered what additional \\
features should be added. For example, while most \\
prescriptions required a simple step in the EMR, \\
some controlled medications required dual-factor \\
authentication. Dr. P requested addition of this \\
feature. Another feature request was for an \\
integrated app to allow Dr. P to seamlessly order \\
and receive lab results. \\
\hline
\end{tabular}

\subsection{Analysis of competing logics}

Combining analyses of the two AR engagements with extant literature, we identify four competing but co-existing logics-logic of care, logic of business, logic of management, and logic of technology - that shaped how the two clinics addressed their RCM challenges. The logics of care, business, and technology closely relate to those identified in a recent study [22], but we refine and contextualize the logics related to RCM and identify a logic of management. Also, we argue that the logic of regulatory oversight [22] is present across the four logics we have identified.

The logic of care focuses on delivering the best possible treatment to the patient. The logic of care is unique to the healthcare industry since it provides meaning to actions [16] of physicians and other clinicians. Clinicians are well trained in the logic of care [46], even though many uncertainties and complexities guide and constrain decisions that shape this logic, such as comorbid medical problems a patient presents, drug interactions and contraindications, the patient's prior medical history, and socio-demographic factors. Based on our observations, the two physicians concerned themselves with treating patients, not primarily with financial or administrative matters [25], which may explain their dependence upon other staff and the researchers to assist them in non-clinical matters. Our conceptualization of the logic of care is similar to the logic of medical professionalism [22, 65]. As Dr. P stated "My primary goal is to see how I can help a patient and to get to the root of the problem. I can't think about anything else if I want to do a good job."

The logic of business seeks actions to receive payments for goods and services that were rendered to the patient and record these transactions appropriately. 
It includes tasks such as medical charge coding, claim submission, electronic remittance advice review, receiving payment (from insurance and/or patient), patient and insurance account reconciliation, sending balance statements to patients, and negotiation and renegotiation of payer contracts. Considering that it required specialized skills (e.g., coding and billing), the logic of business created much more significant problems and was much more costly for these clinics to execute. The focus on the logic of business is salient to healthcare because of the complex and costly reimbursement system in the US. While the logic of private sector managerialism suggested in a recent study [22] overlaps to a degree with the logic of business, their definition includes some tasks that in our view belong to the next logic.

The logic of management seeks sufficient attention to organizing day-to-day activities in a healthcare organization. It is similar to the logic of private sector managerialism [22]. However, based on observations during the two AR studies, separating the logic of business and the logic of management made sense given that specialized knowledge is needed to manage the logic of business in healthcare organizations. The logic of management includes managerial attention to ongoing tasks such as hiring, training, scheduling, evaluating, and terminating staff; communicating with payers (e.g., requesting prior authorization for treatment and drugs, eligibility and benefits, claim resolution); managing medical supply inventory; negotiating with vendors; managing bank accounts and business credit cards; managing payroll, and managing accounts payable. It also includes periodic tasks such as medical licensing; credentialing and re-credentialing with different payers; managing practice-related insurances such as malpractice; and maintaining state and federal certifications (needed, for example, to prescribe controlled medications). Each of these tasks demanded the physician's time and ongoing attention. In the family practice clinic, when Dr. $M$ delegated the purchase of medical supplies to a medical assistant in fall 2019, she ended up with 2year worth of inventory of gloves, masks, and some medications. Exasperated, Dr. M noted, "Organizing is my enemy. I wish they had taught us about these things in medical school and during residency." Dr. P made a similar comment.

Finally, a healthcare organization must select appropriate IT (hardware and software) to manage needs related to patient care, reimbursement, and dayto-day activities. Accordingly, the logic of technology seeks to provide IT support to help deliver clinical and non-clinical services efficiently and effectively. The logic of technology also considers integration of multiple technologies amidst ongoing concerns of patient privacy, security, and continuity of day-to-day operations. In the two clinics, the logic of technology was instantiated differently: the primary care clinic utilized a best-of-breed approach [13], while the psychiatry clinic utilized an integrated EMR-RCM approach. Still, both clinics suffered when it came to reimbursement for their services, i.e. the logic of business. The reason for this was the enormous complexity of the revenue cycle involving multiple third-party payers with their numerous payment plans. Often, the claim processing involved several intermediaries, each of which may have its own IT integration requirements. We see an overlap of technical design logic [22] with our definition of the logic of technology, although we believe our definition covers not only design but also issues related to implementation and de-implementation of various HIT. Dr. P stated, "The difficulty of selecting IT to support RCM when one doesn't understand the complexity [of the RCM] is overwhelming. Not getting paid for months is very stressful when you are made to believe by a vendor that [the RCM] is seamless and painless."

A recent study [22] identified regulatory oversight logic in the context of EMR implementation. We contend that the regulatory oversight logic is present in all the four logics we identified, and therefore it does not represent a unique logic. For example, the logic of care includes regulatory oversight in the form of frequent audits by payers. The logic of business includes rules for maximum allowable payments for different billing codes based on the physician-specific contracted amounts. The logic of management includes attention to specific rules, such as who can be credentialed, when a physician can and must renew their license, and when a physician can prescribe a certain class of drugs. Finally, the logic of technology contains elements of regulatory oversight because of the Health Insurance Portability and Accountability Act (HIPAA), Payment Card Industry Data Security Standard (PCI), and other regulations.

\section{Discussion}

This paper investigates how the implementation of an EMR system impacts RCM and financial sustainability in healthcare organizations. Drawing on institutional logics perspective, we analyze experiences from two AR engagements that leveraged EMR implementations to improve RCM in small medical clinics.

\subsection{Theoretical contribution}

We contribute to the HIT literature by identifying four competing institutional logics-logic of care, 
logic of business, logic of management, and logic of technology - related to the healthcare revenue cycle. These logics shaped how the two clinics managed their revenue cycle after they had implemented an EMR system. Based on our AR experiences, we find that the decision-makers (physicians) at the two clinics had to reconcile competing logics. For example, they had to continually shift their attention from care delivery (logic of care) to improving cash flow to financially sustain the practice (logic of business). Often, the decision-makers had to invest time and resources to overcome constraints related to logic (e.g., implementation of FP-Sys2 and FP-Sys3 at the family practice, and PP-Sys 2 at the psychiatry practice to address the logic of technology). We extend previous research on competing logics in EMR implementation [22] to improve our understanding of how institutional logics shape healthcare organizations' IT-enabled RCM in the wake of EMR implementations.

While IT transformed the practices and information exchanges among internal and external stakeholders in the two clinics (thereby suggesting some degree of complementarity between the logic of technology and the other logics), IT investments did not necessarily come to rescue in helping the clinics overcome the burden of a dysfunctional reimbursement system (addressing which would require federal and state-level policy interventions). Unfortunately, we conclude that IT by itself cannot improve the RCM situation for resource-constrained practices. The contextual findings from this study may encourage IS researchers to further examine the conditions in which HIT investments yield immediate business value for various stakeholders.

Finally, building on the few recent studies [7, 8], we draw the attention of IS researchers to RCM processes and challenges and invite them to further examine this understudied but fertile area that has a long history of IT use [26, 28].

\subsection{Practical contribution}

This research also offers several practical contributions. First, contrary to the belief that a medical practitioner operating a private clinic needs to only focus on the logic of care, our findings suggest that the practitioner must wear multiple hats and pay attention to all four logics. This is a challenge for most practitioners because their training primarily focuses on the logic of care [46]. Our research highlights the need for practitioners to invest in learning about the specifics of the logic of business, the logic of management, and the logic of technology. Unfortunately, learning about these logics may not be easy given that, to our knowledge, medical colleges do not yet offer programs to teach related skills [46].
Second, despite the higher initial cost, selecting a fully integrated EMR-RCM system from the start (rather than trying to integrate these systems later) seems to be a better strategy. The family practice clinic's "best-of-breed" strategy [13] to select FPEMR (even if it was rated highly in ease-of-use) and then try to integrate it with an RCM system proved counter-productive. Third, while all organizations face the logics of business and management, the complexity of the healthcare context makes these logics more challenging in healthcare organizations, especially in small practices. Finally, we observed that the coding and billing in the family practice clinic were far more complex (with more diagnosis and billing codes) than other specialty practices. As such, it is difficult to sustain small independent general practices as their revenue is often not enough to pay for separate billing and coding specialists.

\section{Conclusion}

Although AR afforded important in-depth insights and theory building, it is important to consider its limitations [66]. First, as AR seeks to achieve practical benefits for the client organization, researchers may not "pick and choose" the problem they wish to investigate [66]. Although the two researchers occasionally worked on non-RCM projects, they mostly focused on IT-enabled RCM [7]. As such, this limitation was not an issue in our study. Second, AR methodology is opportunistic and may, therefore, diminish the researcher's ability to control the research process and outcomes [66]. In this research, both researchers helped the small medical clinics to improve their RCM while focusing on the theoretical and practical contributions to knowledge, as described above. Therefore, the potential limitations of AR did not affect the contribution of this research in a significant way.

In conclusion, this study provides insights into the implementation of EMR and RCM systems in two small medical clinics through the lens of institutional logics. Specifically, the research offers contributions to both theory and practice by building on recent work [22] to improve our understanding of how institutional logics shape IT-enabled RCM in the wake of EMR implementations.

\section{References}

[1] Fichman, R.G., Kohli, R., and Krishnan, R., "Editorial Overview-the Role of Information Systems in Healthcare: Current Research and Future Trends", Information Systems Research, 22(3), 2011, pp. 419-428.

[2] Lin, S.C., Jha, A.K., and Adler-Milstein, J., "Electronic Health Records Associated with Lower Hospital Mortality 
after Systems Have Time to Mature", Health affairs, 37(7), 2018, pp. 1128-1135.

[3] Agarwal, R., Gao, G., Desroches, C., and Jha, A.K., "Research Commentary - the Digital Transformation of Healthcare: Current Status and the Road Ahead", Information Systems Research, 21(4), 2010, pp. 796-809.

[4] Sharma, L., Chandrasekaran, A., Boyer, K.K., and Mcdermott, C.M., "The Impact of Health Information Technology Bundles on Hospital Performance: An Econometric Study", Journal of Operations Management, 41(2016, pp. 25-41.

[5] Berger, S., Fundamentals of Health Care Financial Management: A Practical Guide to Fiscal Issues and Activities, Jossey-Bass, 3rd edn, San Francisco, CA, 2008. [6] Lee, S.J., Abbey, J.D., Heim, G.R., and Abbey, D.C., "Seeing the Forest for the Trees: Institutional Environment Impacts on Reimbursement Processes and Healthcare Operations", Journal of Operations Management, 47(2016, pp. 71-79.

[7] Singh, R., Mindel, V., and Mathiassen, L., "It-Enabled Revenue Cycle Transformation in Resource-Constrained Hospitals: A Collaborative Digital Options Inquiry", Journal of Management Information Systems, 34(3), 2017, pp. 695726.

[8] Mindel, V., and Mathiassen, L., "Contextualist Inquiry into Hospital Revenue Cycle Transformation: Bridging Research and Practice", Journal of the Association for Information Systems, 16(12), 2015, pp. 1016-1057.

[9] Mcdermott, P., Jones, J., and Stuckey, L., "Maintaining Revenue Cycle Health During It Change", Healthcare Financial Management, 66(9), 2012, pp. 58-65.

[10] Romanow, D., Rai, A., and Keil, M., "Cpoe-Enabled Coordination: Appropriation for Deep Structure Use and Impacts on Patient Outcomes", MIS Quarterly, 42(1), 2018, pp. 189-212.

[11] Kim, K.K., and Michelman, J.E., "An Examination of Factors for the Strategic Use of Information Systems in the Healthcare Industry", MIS Quarterly, 14(2), 1990, pp. 201215.

[12] Kohli, R., and Tan, S.S.-L., "Electronic Health Records: How Can Is Researchers Contribute to Transforming Healthcare?", MIS Quarterly, 40(3), 2016, pp. 553-573.

[13] Angst, C.M., Wowak, K.D., Handley, S.M., and Kelley, K., "Antecedents of Information Systems Sourcing Strategies in Us Hospitals: A Longitudinal Study", MIS Quarterly, 41(4), 2017, pp. 1129-1152.

[14] Venkatesh, V., Zhang, X., and Sykes, T.A., "“Doctors Do Too Little Technology": A Longitudinal Field Study of an Electronic Healthcare System Implementation", Information Systems Research, 22(3), 2011, pp. 523-546.

[15] Thornton, P.H., and Ocasio, W., "Institutional Logics and the Historical Contingency of Power in Organizations: Executive Succession in the Higher Education Publishing Industry, 1958-1990", American Journal of Sociology, 105(3), 1999, pp. 801-843.

[16] Friedland, R., and Alford, R.R., "Bringing Society Back In: Symbols, Practices, and Institutional Contradictions. Ww Powell, Pj Dimaggio, Eds. The New Institutionalism in Organizational Analysis", in (Editor, 'ed.'^'eds.'): Book Bringing Society Back In: Symbols, Practices, and Institutional Contradictions. Ww Powell, Pj Dimaggio, Eds. The New Institutionalism in Organizational Analysis, University of Chicago Press, Chicago, 1991
[17] Ocasio, W., "Towards an Attention-Based View of the Firm", Strategic Management Journal, 18(S1), 1997, pp. 187-206.

[18] Thornton, P.H., "The Rise of the Corporation in a Craft Industry: Conflict and Conformity in Institutional Logics", Academy of Management Journal, 45(1), 2002, pp. 81-101. [19] Pache, A.-C., and Santos, F., "Inside the Hybrid Organization: Selective Coupling as a Response to Competing Institutional Logics", Academy of Management Journal, 56(4), 2013, pp. 972-1001.

[20] Lee, M.-D.P., and Lounsbury, M., "Filtering Institutional Logics: Community Logic Variation and Differential Responses to the Institutional Complexity of Toxic Waste", Organization Science, 26(3), 2015, pp. 847866.

[21] Reay, T., and Hinings, C.R., "Managing the Rivalry of Competing Institutional Logics", Organization studies, 30(6), 2009, pp. 629-652.

[22] Hansen, S., and Baroody, A.J., "Electronic Health Records and the Logics of Care: Complementarity and Conflict in the Us Healthcare System", Information Systems Research, 31(1), 2020, pp. 57-75.

[23] Nigam, A., and Ocasio, W., "Event Attention, Environmental Sensemaking, and Change in Institutional Logics: An Inductive Analysis of the Effects of Public Attention to Clinton's Health Care Reform Initiative", Organization Science, 21(4), 2010, pp. 823-841.

[24] Tseng, P., Kaplan, R.S., Richman, B.D., Shah, M.A., and Schulman, K.A., "Administrative Costs Associated with Physician Billing and Insurance-Related Activities at an Academic Health Care System", Jama, 319(7), 2018, pp. 691-697.

[25] Malvey, M., Simple Systems, Complex Environments: Hospital Financial Information Systems, Sage Publications, Beverly Hills, CA, 1981.

[26] Lindberg, D.A., The Growth of Medical Information Systems in the United States, Lexington Books, Lexington, MA, 1979.

[27] Castellano, M., and Scibetta, S., "An Automatic Response: Looking to Improve Your Revenue Cycle? For Unc Hospitals, Technology Was Key", Healthcare Financial Management, 59(9), 2005, pp. 90-93.

[28] Fisher, J.H., "Innovation in Medical System Design: The Computer-Human Interface", in (Editor, 'ed.'^'eds.'): Book Innovation in Medical System Design: The ComputerHuman Interface, American Medical Informatics Association, 1984, pp. 561-563.

[29] Alford, R.R., and Friedland, R., Powers of Theory: Capitalism, the State, and Democracy, Cambridge University Press, 1985.

[30] Thornton, P.H., and Ocasio, W., "Institutional Logics", The Sage handbook of organizational institutionalism, 840(2008, pp. 99-128.

[31] Meyer, J.W., and Rowan, B., "Institutionalized Organizations: Formal Structure as Myth and Ceremony", American Journal of Sociology, 83(2), 1977, pp. 340-363.

[32] Berente, N., and Yoo, Y., "Institutional Contradictions and Loose Coupling: Postimplementation of Nasa's Enterprise Information System", Information Systems Research, 23(2), 2012, pp. 376-396.

[33] Greenwood, R., Díaz, A.M., Li, S.X., and Lorente, J.C., "The Multiplicity of Institutional Logics and the 
Heterogeneity of Organizational Responses", Organization Science, 21(2), 2010, pp. 521-539.

[34] Marquis, C., and Lounsbury, M., "Vive La Résistance: Competing Logics and the Consolidation of Us Community Banking", Academy of Management Journal, 50(4), 2007, pp. $799-820$.

[35] Townley, B., "The Institutional Logic of Performance Appraisal", Organization studies, 18(2), 1997, pp. 261-285.

[36] Jones, C., and Livne-Tarandach, R., "Designing a Frame: Rhetorical Strategies of Architects", Journal of Organizational Behavior: The International Journal of Industrial, Occupational and Organizational Psychology and Behavior, 29(8), 2008, pp. 1075-1099.

[37] Rao, H., Monin, P., and Durand, R., "Institutional Change in Toque Ville: Nouvelle Cuisine as an Identity Movement in French Gastronomy", American Journal of Sociology, 108(4), 2003, pp. 795-843.

[38] Suddaby, R., and Greenwood, R., "Rhetorical Strategies of Legitimacy", Administrative Science Quarterly, 50(1), 2005, pp. 35-67.

[39] Berente, N., Lyytinen, K., Yoo, Y., and Maurer, C., "Institutional Logics and Pluralistic Responses to Enterprise System Implementation: A Qualitative Meta-Analysis", MIS Quarterly, 43(3), 2019, pp. 873-902.

[40] Qiu, Y., Gopal, A., and Hann, I.-H., "Logic Pluralism in Mobile Platform Ecosystems: A Study of Indie App Developers on the Ios App Store", Information Systems Research, 28(2), 2017, pp. 225-249.

[41] Dang, D., "Institutional Logics and Their Influence on Enterprise Architecture Adoption", Journal of Computer Information Systems, 2019, pp. 1-11.

[42] Gawer, A., and Phillips, N., "Institutional Work as Logics Shift: The Case of Intel's Transformation to Platform Leader", Organization studies, 34(8), 2013, pp. 1035-1071.

[43] Hinings, B., Gegenhuber, T., and Greenwood, R., "Digital Innovation and Transformation: An Institutional Perspective", Information and Organization, 28(1), 2018, pp. 52-61.

[44] Scott, W.R., Ruef, M., Mendel, P.J., and Caronna, C.A., Institutional Change and Healthcare Organizations: From Professional Dominance to Managed Care, University of Chicago Press, 2000.

[45] Jensen, T.B., Kjærgaard, A., and Svejvig, P., "Using Institutional Theory with Sensemaking Theory: A Case Study of Information System Implementation in Healthcare", Journal of Information Technology, 24(4), 2009, pp. 343-353.

[46] Dunn, M.B., and Jones, C., "Institutional Logics and Institutional Pluralism: The Contestation of Care and Science Logics in Medical Education, 1967-2005", Administrative Science Quarterly, 55(1), 2010, pp. 114-149. [47] Rapoport, R.N., "Three Dilemmas in Action Research", Human Relations, 23(6), 1970, pp. 499-513.

[48] Davison, R., Martinsons, M.G., and Kock, N., "Principles of Canonical Action Research", Information Systems Journal, 14(1), 2004, pp. 65-86.

[49] Baskerville, R.L., and Wood-Harper, A.T., "A Critical Perspective on Action Research as a Method for Information Systems Research", Journal of Information Technology, 11(3), 1996, pp. 235-246.

[50] Susman, G.I., and Evered, R.D., "An Assessment of the Scientific Merits of Action Research", Administrative Science Quarterly, 23(4), 1978, pp. 582-603.
[51] Baskerville, R.L., and Wood-Harper, A.T., "Diversity in Information Systems Action Research Methods", European Journal of Information Systems, 7(2), 1998, pp. 90-107.

[52] Van De Ven, A.H., Engaged Scholarship: A Guide for Organizational and Social Research, Oxford University Press Inc., New York, USA, 2007.

[53] Mårtensson, P., and Lee, A.S., "Dialogical Action Research at Omega Corporation", MIS Quarterly, 2004, pp. 507-536.

[54] Iversen, J.H., Mathiassen, L., and Nielsen, P.A., "Managing Risk in Software Process Improvement: An Action Research Approach", MIS Quarterly, 28(3), 2004, pp. 395-433.

[55] Lindgren, R., Henfridsson, O., and Schultze, U., "Design Principles for Competence Management Systems: A Synthesis of an Action Research Study", MIS Quarterly, 28(3), 2004, pp. 435-472.

[56] Davison, R.M., "Gss and Action Research in the Hong Kong Police Force", Information Technology and People, 14(1), 2001, pp. 60-77.

[57] Braa, J., Monteiro, E., and Sahay, S., "Networks of Action: Sustainable Health Information Systems across Developing Countries", MIS Quarterly, 28(3), 2004, pp. 337-362.

[58] Kohli, R., and Kettinger, W.J., "Informating the Clan: Controlling Physicians' Costs and Outcomes", MIS Quarterly, 28(3), 2004, pp. 363-394.

[59] Davidson, E.J., and Heslinga, D., "Bridging the It Adoption Gap for Small Physician Practices: An Action Research Study on Electronic Health Records", Information Systems Management, 24(1), 2007, pp. 15-28.

[60] Baird, A., Davidson, E., and Mathiassen, L., "Reflective Technology Assimilation: Facilitating Electronic Health Record Assimilation in Small Physician Practices", Journal of Management Information Systems, 34(3), 2017, pp. 664694.

[61] Chiasson, M.W., Germonprez, M., and Mathiassen, L., "Pluralist Action Research: A Review of the Information Systems Literature", Information Systems Journal, 19(1), 2008, pp. 31-54.

[62] Mckay, J., and Marshall, P., "The Dual Imperatives of Action Research", Information Technology and People, 14(1), 2001, pp. 46-59.

[63] Checkland, P.B., Systems Thinking, Systems Practice, John Wiley \& Sons, Ltd., Chichester, 1981.

[64] Davison, R.M., Martinsons, M.G., and Ou, C.X., "The Roles of Theory in Canonical Action Research", MIS Quarterly, 2012, pp. 763-786.

[65] Mcdonald, R., Cheraghi-Sohi, S., Bayes, S., Morriss, R., and Kai, J., "Competing and Coexisting Logics in the Changing Field of English General Medical Practice", Social Science \& Medicine, 93(2013, pp. 47-54.

[66] Baskerville, R., "Investigating Information Systems with Action Research", Communications of the AIS, 2(19), 1999, pp. online. 